\title{
Recent Advances and Future Perspectives on Microfluidic Liquid Handling
}

\author{
Nam-Trung Nguyen *, Majid Hejazian, Chin Hong Ooi and Navid Kashaninejad \\ Queensland Micro- and Nanotechnology Centre, Nathan Campus, Griffith University, 170 Kessels Road, \\ Brisbane, QLD 4111, Australia; majid.hejazian@griffithuni.edu.au (M.H.); \\ chinhong.ooi@griffithuni.edu.au (C.H.O.); n.kashaninejad@griffith.edu.au (N.K.) \\ * Correspondence: nam-trung.nguyen@griffith.edu.au; Tel.: +61-(0)7373-53921
}

Academic Editor: Shih-Kang Fan

Received: 23 May 2017; Accepted: 8 June 2017; Published: 12 June 2017

\begin{abstract}
The interdisciplinary research field of microfluidics has the potential to revolutionize current technologies that require the handling of a small amount of fluid, a fast response, low costs and automation. Microfluidic platforms that handle small amounts of liquid have been categorised as continuous-flow microfluidics and digital microfluidics. The first part of this paper discusses the recent advances of the two main and opposing applications of liquid handling in continuous-flow microfluidics: mixing and separation. Mixing and separation are essential steps in most lab-on-a-chip platforms, as sample preparation and detection are required for a variety of biological and chemical assays. The second part discusses the various digital microfluidic strategies, based on droplets and liquid marbles, for the manipulation of discrete microdroplets. More advanced digital microfluidic devices combining electrowetting with other techniques are also introduced. The applications of the emerging field of liquid-marble-based digital microfluidics are also highlighted. Finally, future perspectives on microfluidic liquid handling are discussed.
\end{abstract}

Keywords: continuous microfluidics; micromixers; cell separation; digital microfluidics; liquid marbles; electrowetting-on-dielectric (EWOD); microfluidic liquid handling

\section{Introduction}

In recent years, the technology of microfluidics has progressed rapidly and become an integral part in many engineering and biomedical applications [1]. Microfluidics has been regarded as the main driver for the paradigm shift in four main areas: molecular analysis, biodefence, molecular biology and microelectronics [2]. The integration of microfluidic components into a single chip led to the advent of lab-on-a-chip (LOC) [3], micro total analysis system ( $\mu$ TAS) [4] and point-of-care (POC) diagnostic devices [5]. In such devices, as well as most biological processes, liquid handling is of great importance, as its quality can significantly affect the end results. According to the way a small liquid amount is handled and manipulated, the field of microfluidics is further classified as continuous-flow microfluidics and digital (droplet-based) microfluidics.

Continuous-flow microfluidics requires an external means to deliver the continuous flow of a single liquid phase or multiple phases through microchannels [6]. The two major and opposing fluid handling tasks of continuous-flow microfluidics are mixing and separation. In particular, mixing of reactants is required to initiate the interactions involved in biological processes such as protein folding and enzyme reactions [7]. For instance, in tumor-on-a-chip microfluidic platforms [8], mixing and delivery of a combination of drugs are necessary. Separation also plays an important role in sample preparation for both analytical chemistry and biological applications [9]. Additionally, cell sorting and separation need to be carried out precisely to develop microfluidic disease models and POC diagnostic tools. Yet, using continuous flow microfluidic technology for mixing and separation 
seems paradoxical. On the one hand, the high surface-to-volume ratio in microfluidics reduces the required sample, and is ideal for biological, biochemical and pharmaceutical applications. On the other hand, the dominant laminar and low-Reynolds-number flow regime delays the mixing and separation process, and requires a larger mixing and separation length scale. This problem indicates the need for innovative mixing/separation methods, especially for LOC applications, where a number of components need to be integrated on a single chip. Traditionally, these methods are categorised as passive (without external energy) and active (in the presence of external energy) techniques [7].

The advantages and disadvantages of passive methods, which utilise chaotic advection to reduce the mixing time, were extensively reviewed by Suh and Kang [10]. The operation principles and mixing capabilities of a broad range of predominantly used micromixers were reviewed by Lee et al. [11]. Ward and Fan [12] categorised and discussed a variety of basic passive microfluidic mixing enhancement techniques, such as slanted wells/pillars, multiphase mixing enhancement and active enhancement techniques, such as thermal enhancement, acoustic waves and flow pulsation. A number of review articles addressed the current state of microfluidic separation techniques. For instance, Sajeesh and Sen presented a comprehensive review on different microfluidic passive and active techniques for particle separation and sorting [9]. In cell biology, microfluidic methods that do not require biochemical labels to isolate and identify cells are referred to as label-free techniques, and have attracted a great deal of attention. Gosset et al. reviewed label-free microfluidic techniques that use the intrinsic properties of the cell, such as its size and other physical signatures [13]. Microfluidic techniques can also be used for detection and separation of cancer cells. Chen et al. [14] discussed high-throughput microfluidic techniques, such as cell-affinity micro-chromatography and magnetically activated sorting. Shields et al. presented recent advances in microfluidic cell separation, along with the challenges in the commercialisation of such devices for practical clinical applications [15].

Combining microfluidics with the science of emulsion, digital microfluidics (DFM) has been developed as a technology dealing with the manipulation of individual droplets, rather than continuous streams of liquid [16]. This field has numerous applications and has the potential to revolutionise various biochemical and biomedical protocols, as well as cell-based assays [17]. DMF has numerous advantages, such as minimum reagent requirement, fast response rates, and more importantly, the capability of performing several parallel procedures [18]. These advantages make DMF an ideal candidate for practical LOC and POC diagnostic devices in clinical use [19]. However, there are still many challenges that need to be addressed in this field, such as droplet evaporation, droplet handling techniques, material selection, etc. [20]. A few recent review articles exist in this emerging field. Samiei et al. [21] reviewed the recent advances in DMF regarding fabrication technology, handling of biological reagents, packaging and portability. Using magnetic actuations to handle the individual droplet is also of great interest. Possibilities and challenges of magnetic digital microfluidics were recently reviewed by Zhang and Nguyen [22].

The scope of the present review paper is summarised in Figure 1. The first part of this paper discusses recent advances of continuous-flow microfluidics in liquid handling, i.e., mixing and separation. In particular, recent progress regarding two key mixing enhancement techniques, namely external forces and complex geometry, are revisited. Subsequently, the paper discusses continuous-flow microfluidic separation techniques such as magnetofluidics, inertial microfluidics, acoustofludics, dielectrophoretics and optofludics. The second part of this paper mainly deals with the advances in both droplet-based DMF and liquid-marble-based DMF. This part discusses the most common methods of droplet-based DMF, such as electrowetting-on-dielectric (EWOD), dielectrophoresis, and magnetic techniques to dispense, move or mix droplets. Finally, the promising field of liquid-marble-based DMF, along with its application as a microbioreactor to culture three-dimensional tissues, will be highlighted. 


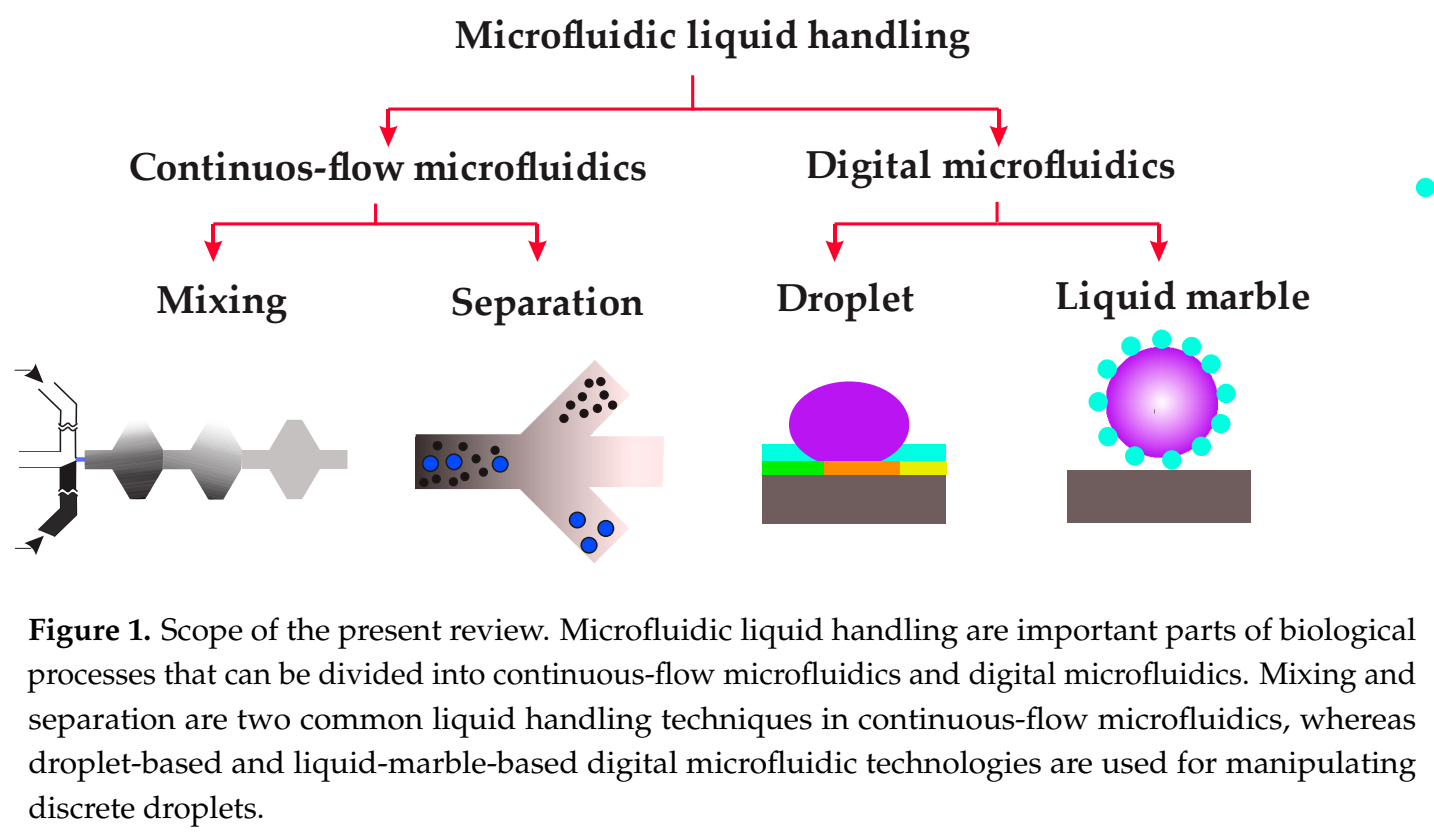

\section{Continuous Flow Microfluidics}

\subsection{Mixing}

Mixing is an essential step in most lab-on-a-chip platforms, as sample preparation is required for a variety of biological and chemical assays. Diffusion-based mixing techniques fail to satisfy the recent demand for rapid and homogeneous mixing. Various strategies have been implemented to enhance the efficiency of continuous-flow microfluidic mixing. In this section, we present the recent advances in continuous mixing with microfluidics.

\subsubsection{Mixing with External Energy Sources}

One of the strategies for increasing mixing efficiency is employing external energy sources to create disturbances, such as acoustic, magnetic, electrostatic. Mass transport of a species in a superparamagnetic solution can be enhanced with an external magnetic field [23]. Utilising embedded electromagnets for magnetofluidic actuation, Mao and Koser [24] demonstrated that the mixing of two streams can be significantly improved. Hejazian and Nguyen [25] proposed a rapid and efficient micromixer using a permanent magnet and a magnetic fluid. The permanent magnet induces a non-uniform magnetic field, and correspondingly, a secondary flow, that mixes a non-magnetic stream with another stream containing diluted ferrofluid. Workamp et al. [26] presented a microfluidic suspension-based mixer with low pressure drop. The mixer consists of a chamber where particles are driven by a moving magnet. Peng et al. [27] proposed a micromixer based on parallel manipulation of individual magnetic microbeads. Rotating magnets generate a circular motion of magnetic beads. As a result, local vortices are created across the microchannel, leading to efficient mixing. Venancio-Marques et al. [28] demonstrated optofluidic mixing in a microfluidic device. As shown schematically in Figure 2, the system consists of three streams, a photosensitive water stream sandwiched between two oil phases. Without light illumination, the flow system is a typical flow-focusing configuration [29]. Light illumination generates water micro-droplets that stir and mix the two continuous oil streams.

Ober et al. [30] examined a rational framework for designing microfluidic active mixers, Figure 3. The micromixers were 3D printed and integrated with a rotating impeller. The capability of continuous mixing of complex fluids was demonstrated. Furthermore, the relationships between mixer dimensions and operating conditions were verified experimentally. 


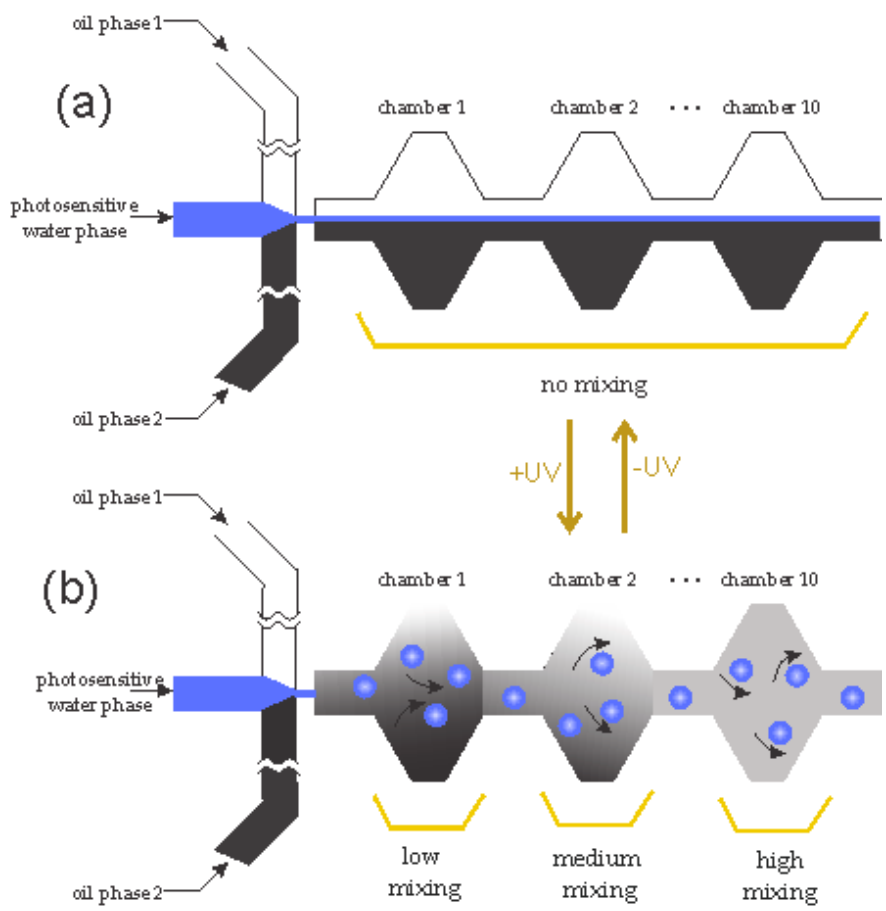

Figure 2. Schematic of the reversible optofluidic mixer developed by Venancio-Marques et al. [28]: (a) when the ultraviolet (UV) is off, the two oil phases are not mixed together; (b) at the presence of UV, the photosensitive water turns into the droplets, causing the mixing between two oil phases. Adapted from [28].

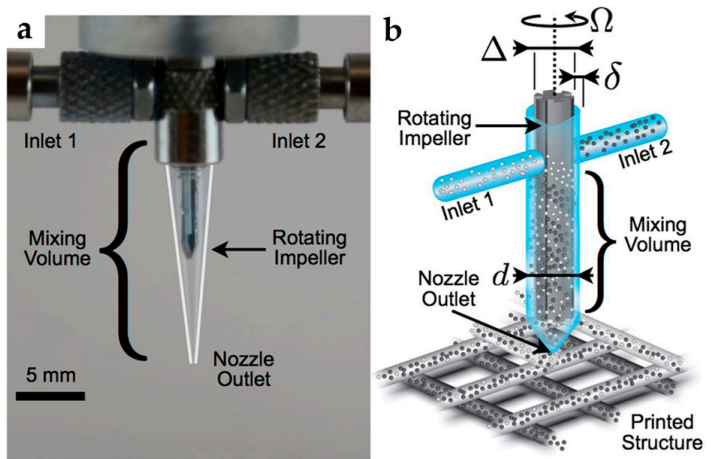

Figure 3. Impeller-based active mixer developed by Ober et al. [30]: (a) optical image of the mixer; (b) representation of the mixing nozzle. Reproduced with permission (granted by PNAS for non-commercial purposes) from [30].

Cui et al. [31] proposed a microfluidic mixer based on acoustically induced vortices created by localized ultrahigh frequency (UHF) acoustic fields. A UHF piezoelectric resonator (SMR) was capable of generating powerful acoustic streaming vortices, resulting in efficient mixing. The authors reported homogeneous mixing, with $87 \%$ mixing efficiency at a Peclet number of 35,520 , within just $1 \mathrm{~ms}$. Fang et al. [32] proposed a micromixer with a streamline herringbone structure, based on total glass. High direct current (DC) voltage-activated migration condition was applied to the microfluidic device as well, and the performance of the mixer was investigated. They reported an efficiency of over $90 \%$ in $20 \mathrm{~mm}$, in a mixing channel of only $300 \mathrm{~nL}$. Shang et al. [33] explored a vortex generated by an acoustic actuator within a circular chamber to improve mixing. The strength of the vortex was tuned by the applied voltage. Their research thus showed that mixing efficiency can be increased by adjusting the voltage. 


\subsubsection{Mixing with Complex Geometries}

Using external actuations to increase the mixing efficiency could be expensive and challenging [29]. Another alternative technique for increasing the mixing efficiency is utilizing relatively complex geometries for chaotic advection. As the flow regime in most microfluidic systems is laminar, the quality of mixing is highly dependent on chaotic advection induced by the geometry of the microchannel. Wu and Nguyen [29] evaluated, both analytically and experimentally, the mixing efficacy of a rectangular microchannel using two-phase hydraulic focusing. To that end, two streams of sheath flow were used to hydraulically focus two streams of sample flow. Their results showed that the focusing ratio was a function of both viscosity ratio and flow rate of sheath and sample flows. To further enhance the mixing efficiency, Nguyen and Huang [34] combined the hydrodynamic focusing technique with time-interleaved segmentation. The results of the paper revealed that, while hydrodynamic focusing could reduce the transversal mixing path, sequential segmentation could also be used to decrease the axial mixing path. It was found that switching frequency and average flow velocity also affected the mixing quality. Cortelezzi et al. [35] proposed a geometrically scalable micromixer capable of achieving fast mixing over a wide range of operating conditions. As shown in Figure 4, the mixer consists of a cylindrical mixing chamber and a cylindrical obstacle. With alternate switching of the inlets to create time-interleaved segmentation, the mixer could reach an efficiency of about $90.8 \%$.
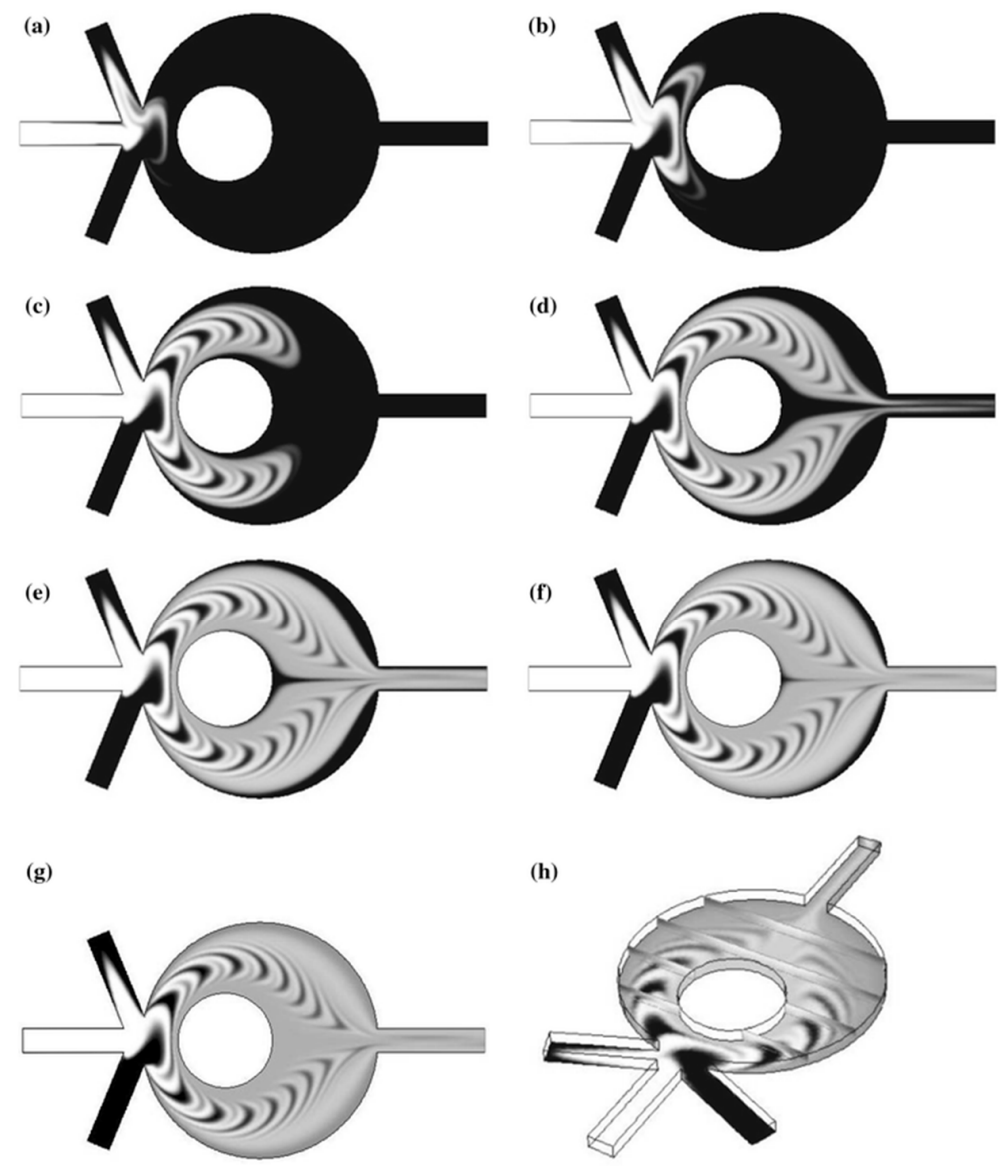

Figure 4. Fast response and geometrically scalable micromixer proposed by Cortelezzi et al. [35]: $(\mathbf{a}-\mathbf{g})$ two-dimensional representation of concentration distribution when time evolves form 2.6, 3.6, 7.6, 11.6, 19.6, 39.6 to $199.6 \mathrm{~s}$, respectively; (h) three-dimensional representation of the concentration distribution at $199.6 \mathrm{~s}$. Reproduced with permission from the original in study [35]. 
Kwak et al. [36] proposed the use of a positive repeated pattern of a staggered herringbone mixer (SHM) in a microchannel to improve mixing efficiency, and compared the results with those obtained from the negative pattern of SHM. It was found that the mixing efficacy would be higher if positive SHM and/or forward flow were used. In particular, a positive pattern SHM could reach completed mixing after two cycles with both forward and reverse flows, while four and five cycles were needed for complete mixing in the negative pattern SHM with forward and reverse flow directions, respectively, Figure 5.

(a)

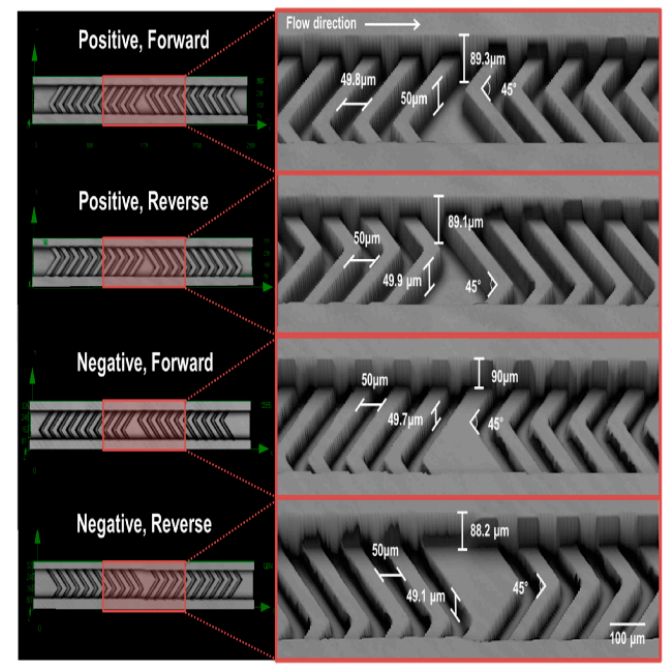

(b)

Positive, Forward

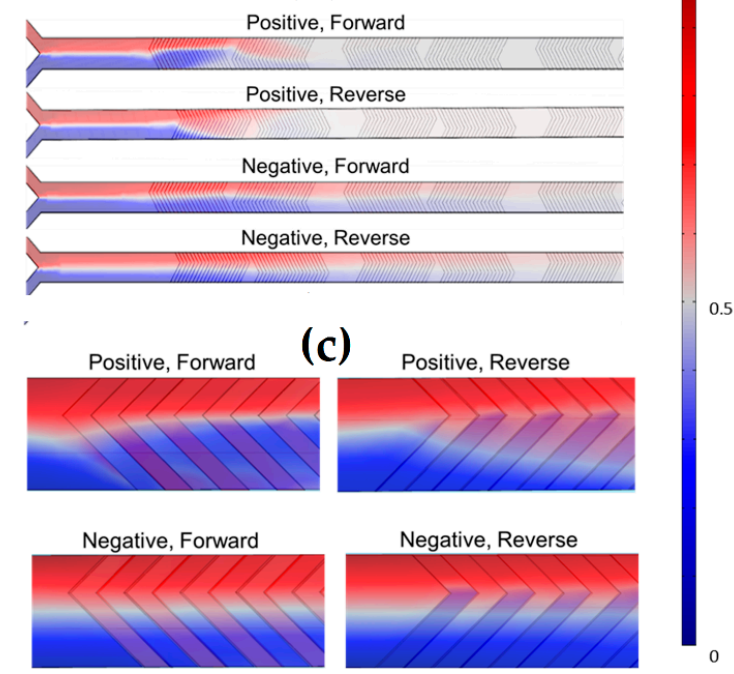

Figure 5. The staggered herringbone mixer (SHM) created by Kwak et al. [36]. (a) Detailed pattern structures and flow directions; (b) Mixing quality after 2.5 cycles in positive and negative SHM structures subject to both forward and reverse flow directions; (c) Top view images of four different SHMs indicating the mixing efficiency at the beginning of the first cycle. Red and blue colors correspond to fluorescence dye and water, respectively, while white color indicates complete mixing. Reproduced with permission (under Creative Commons Attribution (CC BY) license) from [36].

Salieb-Beugelaar et al. [37] presented microfluidic 3D helix mixers for controlled chemical reactions. The authors created the complex channel geometry with thread embedded in polydimethylsiloxane (PDMS). The threads created double helix and triple helix structures in the same device.

Adam and Hashim [38] reported the design and the fabrication of a micromixer with short turns and showed that it could reach a mixing efficiency of $98 \%$ at Reynolds number less than 2 . Sivashankar et al. [39] proposed a micromixer with a twisted structure to enhance mixing. The 3D microfluidic mixer was fabricated by laser micromachining. The results showed that good mixing can be achieved with more than three mixing units. Wang et al. [40] used triangle baffles embedded in a microchannel to enhance mixing. The simulation results show that mixing efficiency can be improved by increasing the apical angle of the triangles from $30^{\circ}$ to $150^{\circ}$. Lehmann et al. [41] performed continuous recalcification of citrated whole blood using a microfluidic herringbone mixer. A herringbone structure was fabricated on top of the channel to generate transverse flows within the microfluidic channel.

Plevniak et al. [42] demonstrated a 3D printed microfluidic mixer for fast mixing of reagents with blood through capillary force. The device was integrated with a smartphone for the point-of-care diagnosis of anemia from a finger-prick blood sample. The results obtained with the device are in line with clinical measurements. Li et al. [43] proposed a microfluidic mixer consisting of an irregular Y junction followed by an observation channel. The mixer was ultra-rapid, as complete mixing was achieved with a mixing time of just $5.5 \mu \mathrm{s}$. The authors interrogated the hairpin formation in the early folding process of human telomere G-quadruplex. 


\subsection{Separation}

In the last two decades, significant advances have been made in the development of continuous-flow microfluidic separation. With continuous injection and collection of samples, a high separation throughput can be achieved. Moreover, continuous-flow microfluidic separation also has the benefit of real-time monitoring, and the potential for the integration with other continuous-flow processes [44]. Based on the unique signature of the sample components, a suitable external force can be chosen for the separation process. The separation of particles and cells can employ a variety of external forces such as hydrodynamic, electrophoretic, dielectrophoretic, magnetophoretic, acoustic, and inertial force [45]. In this section, we explore the current range of continuous separation methods.

\subsubsection{Magnetofluidic Separation}

Continuous-flow magnetofluidic separation has recently gained considerable interest from the research community. Due to the contactless nature of magnetic force, magnetofluidic methods do not alter the $\mathrm{pH}$ level or the temperature of the sample, and as a result, it has no negative effect on the viability of cells [45-47]. Magnetofluidic separation of cells and particles is categorised into two main concepts: positive and negative magnetophoresis. If the magnetic susceptibility of the medium fluid is higher than that of the particles, negative magnetophoresis occurs, and vice versa. Over the last decade, a number of reviews have been published on magnetofluidics, reporting a diverse range of techniques for separation of particles and cells, based on negative and positive magnetophoresis [47-51]. Superparamagnetic carrier fluids, such as ferrofluid, create a secondary flow towards the source of a magnetic field. This phenomenon is called magnetoconvection [23,52]. Exploiting magnetoconvection, a highly size-sensitive separation of microparticles was achieved within a microchannel [53]. Using two arrays of attracting magnets, non-magnetic polystyrene micro-particles were captured in different locations along a straight microchannel. Applying a similar concept, Zhou et al. [54] introduced a platform for simultaneous capture of non-magnetic and magnetic particles. For this purpose, an external magnetic field was generated with a permanent magnet positioned next to a T-junction in the microchannel.

Particle focusing with magnetofluidics has been reported using two sets of repelling magnets [49,51,55]. Liang and Xuan [56] reported sheathless focusing of non-magnetic particles. A T-microchannel, a single permanent magnet, and diluted ferrofluid as the superparamagnetic carrier fluid, were used for this purpose. A relatively strong magnetic field gradient should be implemented to achieve high efficiency and size sensitivity. For instance, decreasing the distance between the external magnetic field source and the fluidic channel is a solution for increasing the magnetic field gradient. Zhou and Wang [57] introduced a convenient and low-cost technique for the enhancement of magnetic field gradient. For this purpose, a prefabricated channel was formed next to the microfluidic channel. A mixture of iron powder and polydimethylsiloxane (PDMS) was injected into the channel. The iron-PDMS structures were placed just a few microns from the microchannel. Separation of nanoparticles with magnetofluidics has also recently gained attention. Wu et al. [58] proposed an efficient method for size-selective separation of magnetic nanospheres using a magnetofluidic device. Two monodisperse nanosphere samples (90 nm and $160 \mathrm{~nm}$ ) were successfully separated from the polydispersing particles solution, with varied particle diameters from 40 to $280 \mathrm{~nm}$.

\subsubsection{Inertial Microfluidics}

Inertial microfluidics is another emerging field of continuous-flow particle separation. Inertial microfluidics is a suitable method for rare cell sorting, due to such various advantages as high throughput, simplicity, precise manipulation and low cost [59,60]. A number of reviews have summarised the existing techniques and designs of inertial microfluidics [59-63]. The inertial force is often combined with other forces, such as hydraulic, magnetic, centrifugal, or hydrodynamic forces, in order to obtain a higher separation efficiency. Ahn et al. [64] designed a sheathless elasto-inertial 
focusing microfluidic separator, and performed a systematic study evaluating the parameters affecting the performance of a microfluidic separator based on inertial microfluidics. The schematic illustration along with the working principles of their fabricated microfluidic separator is shown in Figure 6.

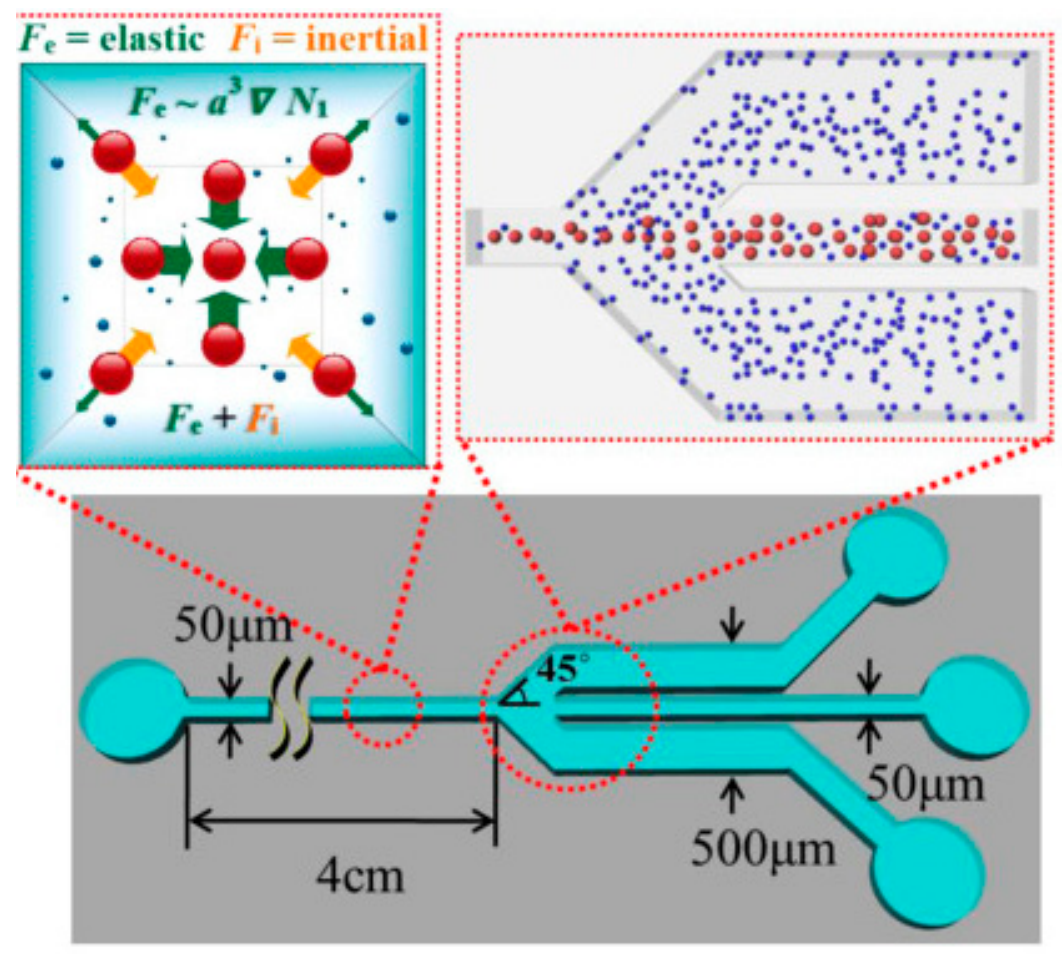

Figure 6. Microfluidic separator based on inertial microfluidics with its working principles developed by Ahn et al. [64]. Reproduced with permission from [64].

Optimisation parameters, such as particle concentration and flow rate, as well as the effect of particle-particle interaction in the separation process, were determined [65]. Combining lift forces and Dean flow drag forces, algae species were separated, based on their shape and size, in a spiral microchannel. Monoraphidium species was successfully separated from the differently shaped Cyanothece, with $77 \%$ separation efficiency.

Zhou et al. [66] demonstrated a hybrid method based on the combination of inertial microfluidics and magnetofluidics for size-selective separation of micro-particles. Spherical diamagnetic polystyrene particles of $10 \mu \mathrm{m}$ and $20 \mu \mathrm{m}$ were successfully separated using this technique. Clime et al. [67] furthermore demonstrated filtration and extraction of pathogens from food samples, utilising hydrodynamic focusing and inertial lateral migration. The microfluidic platform was capable of removing up to $50 \%$ of debris from ground beef samples.

\subsubsection{Acoustofluidic Separation}

The use of acoustic waves is another technique that has been used for continuous particle separation with microfluidics. Because of such advantages as simplicity of design, low-cost, and biocompatibility due to its contactless nature, acoustic wave devices have been integrated with microfluidic devices. A number of recent reviews reported on the different configurations of acoustofluidic devices [68-73]. Mathew et al. [74] developed a two-dimensional dynamic model for tracing the path of microparticles in continuous-flow microfluidics employing acoustic waves. The effect of parameters, such as acoustic energy density and initial vertical location, on the displacement of microparticles were examined with this model. Shields et al. [75] designed a multi-stage microfluidic platform for separation of cancer cells from blood. In the first module, the acoustic standing wave is exploited for immediate alignment 
of cells. Magnetic separation techniques then purify and capture individual cells for on-chip analyses, in the next two steps. $\mathrm{Ng}$ et al. [76] designed a flow-rate-insensitive device for continuous particle sorting, Figure 7. The device uses surface acoustic waves that combine both standing and travelling wave components to create pressure nodes. The particles were trapped in locations with a stable pressure based on their size, and separated through a distinct exit.

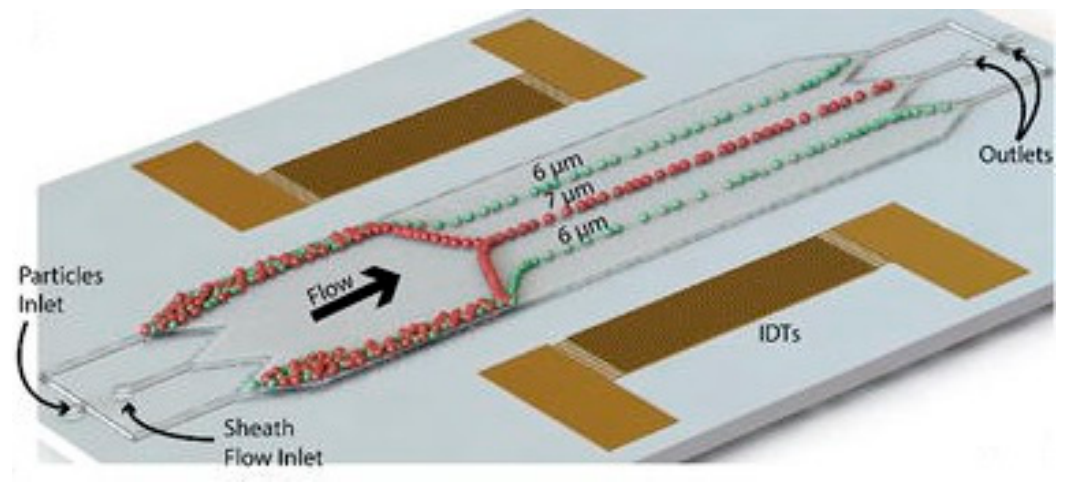

Figure 7. Schematic illustration of flow-rate-insensitive device for continuous particle sorting, designed by $\mathrm{Ng}$ et al. [76]. Reproduced with permission from [64,76].

\subsubsection{Dielectrophoretic Separation}

Dielectrophoretic method has been another area of interest for continuous particle separation with microfluidics in recent years. The use of dielectrophoretic force with microfluidics for continuous particle separation has advantages such as low cost, rapidity, size sensitivity, and selectivity. Previously published reviews discuss a variety of techniques used for dielectrophoretics-based cell and particle separation [77-81]. Cui et al. [82] proposed a dielectrophoresis (DEP)-based method for size-based particle separation. The authors demonstrated the extraction of larger particles, retaining small particles, and also eluting mid-size particles using pulsed dielectrophoresis. Kim et al. [83] proposed an integrated Dielectrophoretic-Magnetic Activated Cell Sorter (iDMACS). The target cell types were sorted based on surface markers, via specific receptor-ligand binding to either DEP or magnetic tags. The device could achieve 900-fold enrichment of multiple bacterial target cell types, with over $95 \%$ purity after a single round of separation. Yang et al. [84] examined dielectrophoresis (DEP)-active hydrophoresis for sorting particles and cells. The device consists of prefocusing and sorting steps, and achieved highly efficient and pure separation of both viable and nonviable Chinese Hamster Ovary $(\mathrm{CHO})$ cells from medium fluid.

\subsubsection{Optofluidic Separation}

Kotari et al. [85] exploited optical radiation pressure for particle separation in a microfluidic device. Figure 8 illustrates the experimental setup for lateral particle sorting which uses SU-8 as a waveguide to irradiate a near-infrared (NIR) laser beam to facilitate the observation of particle distribution. Using scattering force, particles are manipulated corresponding to the amount of light received by them. Polystyrene beads were successfully transported by the optical scattering force with an energy density of less than $10 \mathrm{~mW} / \mathrm{mm}^{2}$. 


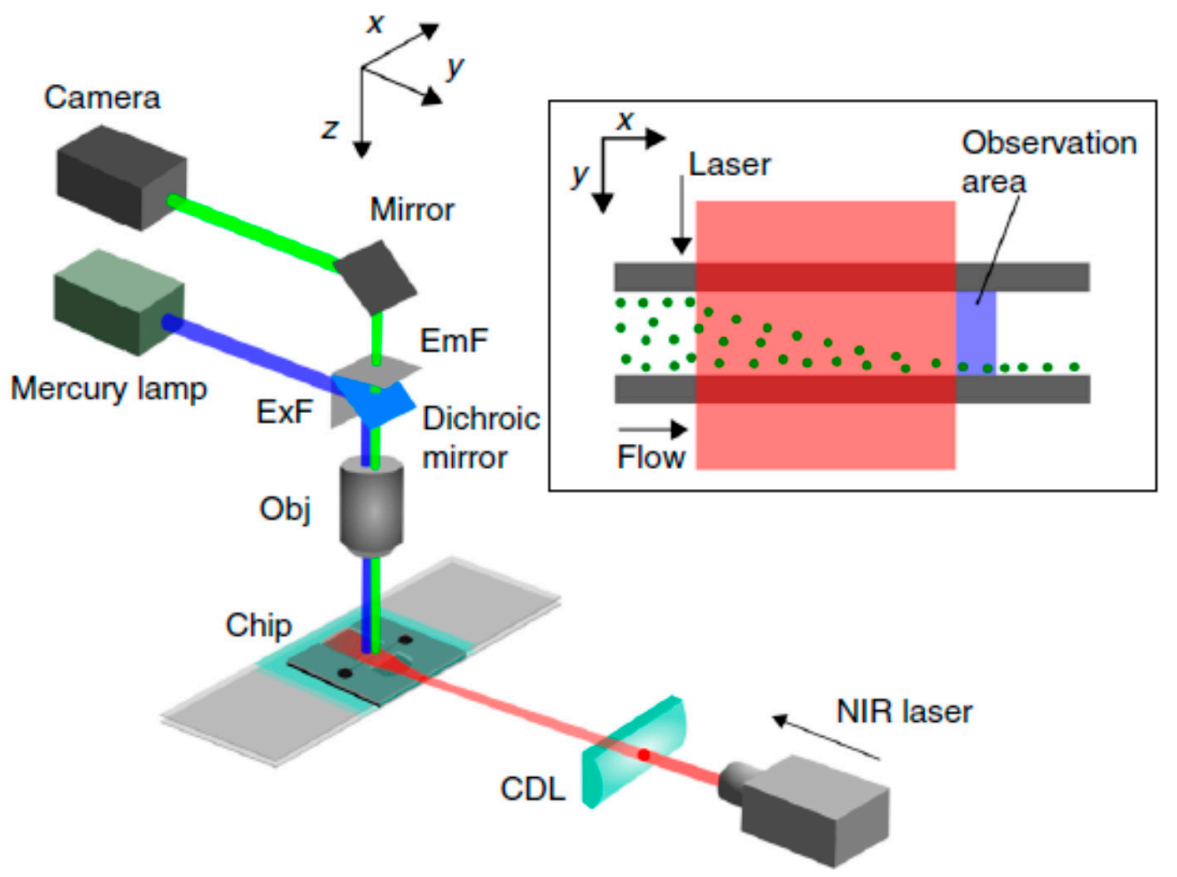

Figure 8. The experimental test rig of microfluidic optical radiation pressure for particle separation developed by Kotari et al. [85]. The SU-8 layer on the microchip guides the near-infrared (NIR) laser beam through the lens. Reproduced with permission from original in study [85].

\subsection{Advanced Continuous-Flow Microfluidics with Combined Mixing and Separation}

For many biological and chemical analyses, mixing of reagents, and subsequent separation from the remaining sample and vice versa, are the main reasons for making these analyses labour-intensive, time-consuming, expensive and cumbersome. The unique feature of microfluidics is that it allows for the integration of both mixing and separating components on a single chip. In addition, incorporating gas-permeable PDMS membranes into such microfluidic platforms allows for the fabrication of advanced microbioreactors, capable of performing a variety of chemical and biological processes. Specialised POC diagnostic platforms, such as lab-on-a-disc, show great promise for fast, reliable and cost-effective immunoassay tools. For example, the lab-on-a-disc platform developed by Kuo and Li [86] allowed for the separation of plasma from whole blood in only six seconds. Subsequently, the plasma-free blood was able to be mixed with related reagents for other diagnostic tests. The microfluidic device for the prothrombin time (PT) test was 15 times faster than the conventional bench-top counterpart. For both diagnostic and therapeutic purposes, high-throughput label-free microfluidic cell sorters are in great demand. Using the passive hydrodynamic approach, Tallapragada et al. [87] proposed a scale-independent method to separate and encapsulate inertial particles, specifically pancreatic islets, in serpentine microchannels. Finally, microfluidic chromatographic platforms have also opened up new avenues for separation chemistry, especially for protein purification [88].

\section{Digital Microfluidics}

Digital microfluidics (DMF) involves the manipulation of small, discrete droplets, usually in the microlitre scale or smaller. The main tasks of DMF involve dispensing droplets, moving droplets, merging droplets or mixing contents within a droplet. Numerous techniques have been developed to perform these tasks, as elaborated on in extensive recent reviews [20-22,89-91]. 


\subsection{Droplet-Based DMF}

DMF devices can have a basic open planar form, where the droplet is placed on a solid planar surface. The plate is usually engineered to provide an energy gradient to drive the droplet. In some cases, a top plate is added to facilitate control of the sandwiched droplet. With proper design, droplets can be moved across the plate in two dimensions. However, the droplet can also be further controlled by constructing channels between the plates, thus restricting the droplet to a one-dimensional movement. The immiscible fluid surrounding the droplet maintains the separation of droplets. Specially treated surfaces in contact with the droplet minimises loss of liquid during transport.

\subsubsection{Electrowetting-on-Dielectric (EWOD) Technique}

One of the most popular techniques in DMF is electrowetting-on-dielectric (EWOD). A droplet is placed between two plates, one of which contains a dielectric layer. A voltage difference across the droplet generates asymmetric droplet contact angles, thus creating a driving force. Switching the voltage difference in a timely manner moves the droplet [92-94]. Optoelectrowetting is a modified version of the EWOD technique, where the voltage switching is accomplished optically $[95,96]$. Recently, Geng et al. [93] reported a pioneering work regarding the use of the dielectrowetting [97] instead of EWOD to manipulate both conductive or non-conductive droplets. This concept removes the need for a top plate and provides easy access to the droplets. The principle operation of such a technique is shown in Figure 9.
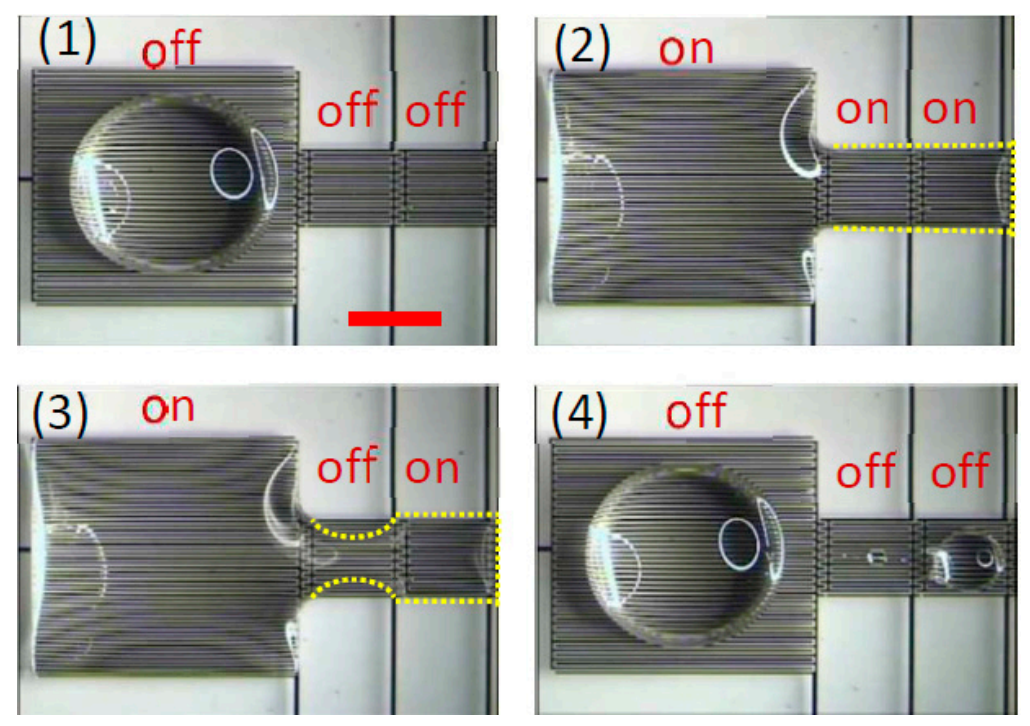

Figure 9. Droplet dispensing using dielectrowetting. (1) A 22- $\mu \mathrm{L}$ sessile droplet of propylene carbonate on the electrode pads. (2) The electrode pads are turned on, spreading the droplet. (3) The middle pad is turned off to pinch off the droplet. (4) All the pads are turned off and droplet separation is complete. Reproduced with permission from the original in study [93].

\subsubsection{Dielectrophoretic Technique}

The dielectrophoresis technique similarly uses electrostatic force, but the droplet itself acts as a dielectric [98,99]. In one of the most recent works, Iwai et al. [100] combine "finger-powered" microfluidics with piezoelectric elements to achieve dielectrophoretic droplet manipulation. The device harnesses the user's mechanical input and converts it into electrostatic energy, which is then used to move the droplets suspended in fluids, Figure 10. 


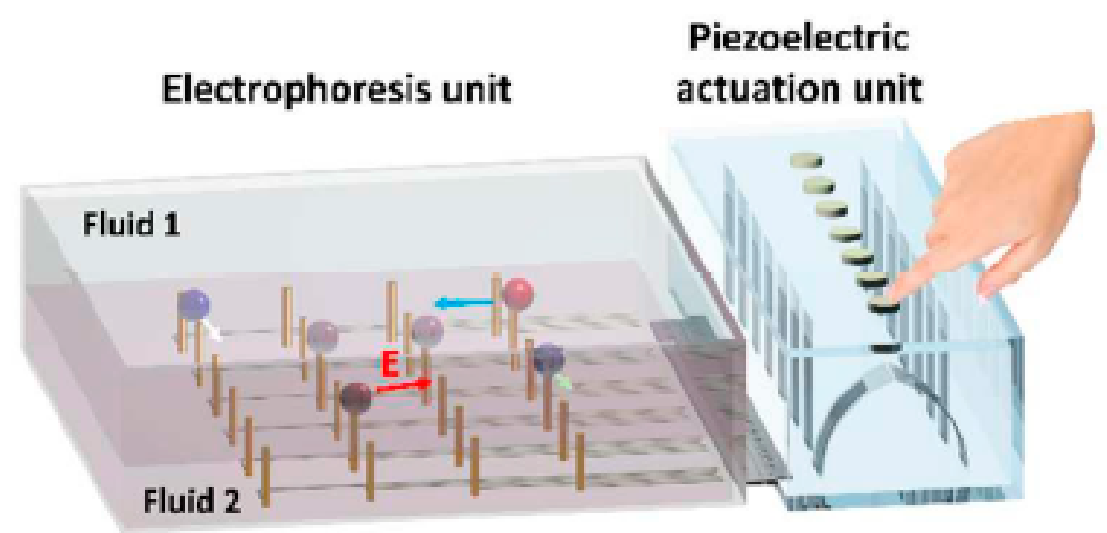

Figure 10. Schematic showing the finger-powered electrophoresis unit. The electrodes are connected to the piezoelectric actuation unit, which can be actuated by pressing on it. The electrophoresis unit contains both the electrode array and the droplets, suspended in a binary fluid. Reproduced with permission from the original in study [100].

\subsubsection{Magnetic-Based Techniques}

Instead of an electric field, a magnetic field can be applied to move droplets containing magnetite via magnetowetting [101]. The magnetic field generates a body force throughout the entire droplet. Displacing a permanent magnet under a ferrofluid droplet creates asymmetric contact angles and moves the droplet.

\subsubsection{Other Techniques}

Droplets can be manipulated using other means such as surface acoustic waves (SAW) [102-104] or thermocapillary forces $[105,106]$. Acoustic energy is generated using a piezoelectric element and transferred to the droplet. As the SAW hit the droplet, energy is transferred onto the droplet, which causes it to de-pin from the surface and move. More energetic SAW can even cause droplets to nebulise. Unlike EWOD, most SAW devices need only one plate. On the other hand, a thermocapillary-based DMF device moves a droplet using capillary forces generated by surface tension gradients which arise from temperature differentials. Nguyen and Huang [107] evaluated the manipulation of droplets in long capillaries under a variable temperature field. In particular, they evaluated the initial behaviour of liquid motion under a transient temperature gradient, both analytically and experimentally.

\subsection{Liquid-Marble-Based DMF}

Another growing field in DMF is the use of liquid marble (LM) as the discrete platform. The LM is a small droplet encapsulated by a hydrophobic coating, which consists of a porous particle layer [108-111]. The hydrophobic and porous shell removes the need for surface treatment, as the droplet is physically isolated from its surroundings. An added benefit is that a LM is able to float on a liquid surface [112,113] and seemingly skid around with low friction [114,115]. As discussed by Ooi and Nguyen [116] in a comprehensive review paper, numerous techniques to manipulate the LM have been derived. Among the most popular techniques is manipulating a LM containing magnetite using a permanent magnet [117-121]. Zhao et al. [120] used an encapsulated LM driven by a permanent magnet as a bioreactor, as illustrated in Figure 11. Furthermore, a LM can be driven by thermo- $[122,123]$ or soluto-capillary forces, and even carry its own propellant whilst doing so [124-126]. 


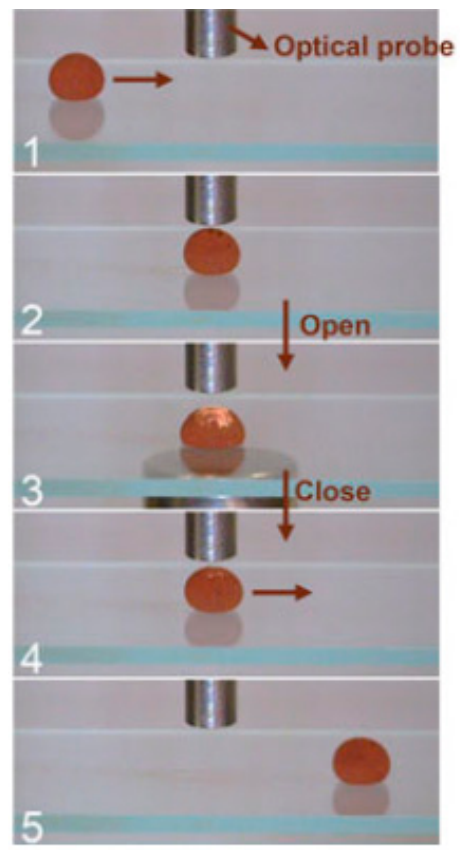

Figure 11. A magnetite-covered LM used as a miniature bioreactor. $(\mathbf{1}, \mathbf{2})$ The LM containing the reactants is moved towards the optical probe using a permanent magnet. (3) The coating of the LM can be "opened" to reveal its contents by increasing the magnetic field. $(4,5)$ The coating opening process is reversed and the LM is moved away from the probe. Reproduced with permission (CC BY license) from original in study [120].

\subsection{Advanced Digital Microfluidic Platforms}

Recent advances in manipulating microdroplets predominantly involve EWOD-based devices. Researchers have pioneered the use of DMF in the immunoprecipitation process [127]. This concept was accomplished using an existing DMF device which combines both EWOD and magnetic manipulation of the droplet [128,129]. DMF has also been used for the first time in solid-phase micro extraction [130], as well as in high field nuclear magnetic resonance spectroscopy [131]. Nanostructure initiator mass spectrometry (NIMS) arrays can be integrated into an EWOD device to conduct enzyme screening, which potentially increases the throughput of the process [132]. On the cost-reduction front, a specially designed EWOD system has been manipulated using a smart phone to conduct chemiluminescence sensing [133].

However, liquid marble has recently shown its potential as an emerging digital microfluidic platform, especially for biological applications. The most prominent application of liquid marble has been cell culture and the ability to form three-dimensional spheroids due to its respirable and non-adhesive coating [134-137]. Liquid marble can be dehydrated to form hollow shells [138], which then is used for drug encapsulation and release [139]. Liquid marble can also be used as a microbioreactor, as it can accommodate liquid volumes across several orders of magnitude and still can be easily handled [118,140]. Recently, a spinning liquid marble has been used to improve mixing [141].

\section{Conclusions and Perspectives}

This paper summarises the most recent and advantageous advances in liquid handling modalities, using both continuous-flow and digital microfluidics. Due to the importance of mixing and separation in biological and chemical procedures, we confined the scope of continuous-flow microfluidics to these two topics. Mixing is an essential step in most lab-on-a-chip platforms, as sample preparation is required for a variety of biological and chemical assays. Diffusion-based mixing techniques fail to satisfy the recent demand for rapid and homogeneous mixing. Advances in two major mixing 
enhancement strategies, i.e., mixing with external energy sources, as well as complex channels geometry, were reviewed. Continuous-flow microfluidic separation also has the benefit of real-time monitoring and the potential for the integration with other continuous-flow processes. Based on the unique signature of the sample components, a suitable external force can be chosen for the separation process. Cutting-edge advances in continuous-flow microfluidic separation techniques, including magnetofluidics, inertial microfluidics, acoustofludics, dielectrophoretics and optofludics, were reviewed and discussed. Emerging applications of combined continuous-flow separation and mixing technologies for more advanced microfluidic platforms, such as diagnostic and therapeutic microbioreactors, lab-on-a-disc and microfluidic chromatography for protein purification, were introduced.

The second part of this paper was dedicated to digital microfluidics for handling microdroplets and liquid marbles. Droplet-based DMF techniques, such as electrowetting-on-dielectric (EWOD), dielectrophoresis, and magnetic methods were discussed. The applications of more advanced combinatorial DMF devices were also introduced. In addition, manipulation techniques for liquid marble as a microbioreactor were presented.

Recent advances in microfluidics indicate that more complex microfluidic structures, especially for mixing applications, could be fabricated with 3D printing. The design freedom provided by 3D printing will allow for novel designs, which to date cannot be obtained with planar micromachining techniques, such as soft lithography with PDMS. Microfluidic cell culture can be considered as the next-generation technique for biomedical and pharmaceutical applications. Liquid marble has emerged as a promising digital microfluidics platform. Continuous-flow microfluidics will continue to be used for applications that require high throughput. However, the problem of bulky external liquid delivery and the need of optical microscopy for characterisation makes continuous-flow microfluidics less suitable for applications with limited sample size. Digital microfluidics with droplets and liquid marbles is the solution for the problem of bulky external systems, as well as the relatively large sample volume. In the near future, we could expect more reports on this unique research area. As most recent works are only on the proof-of-concept of liquid-marble-based digital microfluidics, automated systems for creating liquid marble and the controlled manipulation of liquid marble, such as coalescence and splitting, are areas of interest for bringing this platform closer to practical use.

Acknowledgments: We acknowledge the Australian Research Council for the grant support DP170100277.

Author Contributions: N.-T.N. developed the structure of the paper. Other authors collected and analysed the literature. All authors wrote the paper.

Conflicts of Interest: The authors declare no conflict of interest.

\section{References}

1. Nguyen, N.-T.; Wereley, S.T. Fundamentals and Applications of Microfluidics; Artech House: London, UK, 2002.

2. Whitesides, G.M. The origins and the future of microfluidics. Nature 2006, 442, 368-373. [CrossRef] [PubMed]

3. Nguyen, N.-T.; Shaegh, S.A.M.; Kashaninejad, N.; Phan, D.-T. Design, fabrication and characterization of drug delivery systems based on lab-on-a-chip technology. Adv. Drug Deliv. Rev. 2013, 65, 1403-1419. [CrossRef] [PubMed]

4. Reyes, D.R.; Iossifidis, D.; Auroux, P.-A.; Manz, A. Micro total analysis systems. 1. Introduction, theory, and technology. Anal. Chem. 2002, 74, 2623-2636. [PubMed]

5. Jung, W.; Han, J.; Choi, J.-W.; Ahn, C.H. Point-of-care testing (POCT) diagnostic systems using microfluidic lab-on-a-chip technologies. Microelectron. Eng. 2015, 132, 46-57. [CrossRef]

6. Kashaninejad, N.; Chan, W.K.; Nguyen, N.-T. Fluid mechanics of flow through rectangular hydrophobic microchannels. In Proceedings of the ASME 2011 9th International Conference on Nanochannels, Microchannels, and Minichannels, Edmonton, AL, Canada, 19-22 June 2011; pp. 647-655.

7. Nguyen, N.-T.; Wu, Z. Micromixers-A review. J. Micromech. Microeng. 2004, 15, R1. [CrossRef]

8. Kashaninejad, N.; Nikmaneshi, M.R.; Moghadas, H.; Kiyoumarsi Oskouei, A.; Rismanian, M.; Barisam, M.; Saidi, M.S.; Firoozabadi, B. Organ-Tumor-on-a-Chip for Chemosensitivity Assay: A Critical Review. Micromachines 2016, 7, 130. [CrossRef] 
9. Sajeesh, P.; Sen, A.K. Particle separation and sorting in microfluidic devices: A review. Microfluid. Nanofluid. 2014, 17, 1-52. [CrossRef]

10. Suh, Y.K.; Kang, S. A Review on Mixing in Microfluidics. Micromachines 2010, 1, 82-111. [CrossRef]

11. Lee, C.-Y.; Chang, C.-L.; Wang, Y.-N.; Fu, L.-M. Microfluidic Mixing: A Review. Int. J. Mol. Sci. 2011, 12, 3263-3287. [CrossRef] [PubMed]

12. Ward, K.; Fan, Z.H. Mixing in microfluidic devices and enhancement methods. J. Micromech. Microeng. 2015, 25, 094001. [CrossRef] [PubMed]

13. Gossett, D.R.; Weaver, W.M.; Mach, A.J.; Hur, S.C.; Tse, H.T.K.; Lee, W.; Amini, H.; Di Carlo, D. Label-free cell separation and sorting in microfluidic systems. Anal. Bioanal. Chem. 2010, 397, 3249-3267. [CrossRef] [PubMed]

14. Chen, J.; Li, J.; Sun, Y. Microfluidic approaches for cancer cell detection, characterization, and separation. Lab Chip 2012, 12, 1753-1767. [CrossRef] [PubMed]

15. Shields, C.W.; Ohiri, K.A.; Szott, L.M.; López, G.P. Translating microfluidics: Cell separation technologies and their barriers to commercialization. Cytom. B Clin. Cytom. 2017, 92, 115-125. [CrossRef] [PubMed]

16. Choi, K.; Ng, A.H.; Fobel, R.; Wheeler, A.R. Digital microfluidics. Annu. Rev. Anal. Chem. 2012, 5, 413-440. [CrossRef] [PubMed]

17. Barbulovic-Nad, I.; Yang, H.; Park, P.S.; Wheeler, A.R. Digital microfluidics for cell-based assays. Lab Chip 2008, 8, 519-526. [CrossRef] [PubMed]

18. Xu, T.; Chakrabarty, K. Parallel scan-like test and multiple-defect diagnosis for digital microfluidic biochips. IEEE Trans. Biomed. Circuits Syst. 2007, 1, 148-158. [CrossRef] [PubMed]

19. Fair, R.B. Digital microfluidics: Is a true lab-on-a-chip possible? Microfluid. Nanofluid. 2007, 3, $245-281$. [CrossRef]

20. Jebrail, M.J.; Bartsch, M.S.; Patel, K.D. Digital microfluidics: A versatile tool for applications in chemistry, biology and medicine. Lab Chip 2012, 12, 2452-2463. [CrossRef] [PubMed]

21. Samiei, E.; Tabrizian, M.; Hoorfar, M. A review of digital microfluidics as portable platforms for lab-on a-chip applications. Lab Chip 2016, 16, 2376-2396. [CrossRef] [PubMed]

22. Zhang, Y.; Nguyen, N.-T. Magnetic digital microfluidics-A review. Lab Chip 2017, 17, 994-1008. [CrossRef] [PubMed]

23. Hejazian, M.; Phan, D.T.; Nguyen, N.T. Mass transport improvement in microscale using diluted ferrofluid and a non-uniform magnetic field. RSC Adv. 2016, 6, 62439-62444. [CrossRef]

24. Mao, L.; Koser, H. Overcoming the Diffusion Barrier: Ultra-Fast Micro-Scale Mixing Via Ferrofluids. In Proceedings of the 2007 International Solid-State Sensors, Actuators and Microsystems Conference (TRANSDUCERS 2007), Lyon, France, 10-14 June 2007; pp. 1829-1832.

25. Hejazian, M.; Nguyen, N.-T. A rapid magnetofluidic micromixer using diluted ferrofluid. Micromachines 2017, 8, 37. [CrossRef]

26. Marcel, W.; Vittorio, S.; Joshua, A.D. A simple low pressure drop suspension-based microfluidic mixer. J. Micromech. Microeng. 2015, 25, 094003.

27. Peng, Z.C.; Hesketh, P.; Mao, W.; Alexeev, A.; Lam, W. A microfluidic mixer based on parallel, high-speed circular motion of individual microbeads in a rotating magnetic field. In Proceedings of the 2011 16th International Solid-State Sensors, Actuators and Microsystems Conference, TRANSDUCERS'11, Beijing, China, 5-9 June 2011; pp. 1292-1295.

28. Venancio-Marques, A.; Barbaud, F.; Baigl, D. Microfluidic mixing triggered by an external LED illumination. J. Am. Chem. Soc. 2013, 135, 3218-3223. [CrossRef] [PubMed]

29. Wu, Z.; Nguyen, N.-T. Rapid Mixing Using Two-Phase Hydraulic Focusing in Microchannels. Biomed. Microdevices 2005, 7, 13-20. [CrossRef] [PubMed]

30. Ober, T.J.; Foresti, D.; Lewis, J.A. Active mixing of complex fluids at the microscale. Proc. Natl. Acad. Sci. USA 2015, 112, 12293-12298. [CrossRef] [PubMed]

31. Cui, W.; Zhang, H.; Zhang, H.; Yang, Y.; He, M.; Qu, H.; Pang, W.; Zhang, D.; Duan, X. Localized ultrahigh frequency acoustic fields induced micro-vortices for submilliseconds microfluidic mixing. Appl. Phys. Lett. 2016, 109, 253503. [CrossRef]

32. Fang, F.; Zhang, N.; Liu, K.; Wu, Z.-Y. Hydrodynamic and electrodynamic flow mixing in a novel total glass chip mixer with streamline herringbone pattern. Microfluid. Nanofluid. 2015, 18, 887-895. [CrossRef] 
33. Shang, X.; Huang, X.; Yang, C. Mixing enhancement by the vortex in a microfluidic mixer with actuation. Exp. Therm. Fluid Sci. 2015, 67, 57-61. [CrossRef]

34. Nguyen, N.-T.; Huang, X. Mixing in microchannels based on hydrodynamic focusing and time-interleaved segmentation: Modelling and experiment. Lab Chip 2005, 5, 1320-1326. [CrossRef] [PubMed]

35. Cortelezzi, L.; Ferrari, S.; Dubini, G. A scalable active micro-mixer for biomedical applications. Microfluid. Nanofluid. 2017, 21,31. [CrossRef]

36. Kwak, T.J.; Nam, Y.G.; Najera, M.A.; Lee, S.W.; Strickler, J.R.; Chang, W.-J. Convex Grooves in Staggered Herringbone Mixer Improve Mixing Efficiency of Laminar Flow in Microchannel. PLoS ONE 2016, 11, e0166068. [CrossRef] [PubMed]

37. Salieb-Beugelaar, B.G.; Gonçalves, D.; Wolf, P.M.; Hunziker, P. Microfluidic 3D Helix Mixers. Micromachines 2016, 7, 189. [CrossRef]

38. Adam, T.; Hashim, U. Design and fabrication of micro-mixer with short turns angles for self-generated turbulent structures. Microsyst. Technol. 2016, 22, 433-440. [CrossRef]

39. Sivashankar, S.; Agambayev, S.; Mashraei, Y.; Li, E.Q.; Thoroddsen, S.T.; Salama, K.N. A "twisted" microfluidic mixer suitable for a wide range of flow rate applications. Biomicrofluidics 2016, 10, 034120. [CrossRef] [PubMed]

40. Wang, L.; Ma, S.; Wang, X.; Bi, H.; Han, X. Mixing enhancement of a passive microfluidic mixer containing triangle baffles. Asia Pac. J. Chem. Eng. 2014, 9, 877-885. [CrossRef]

41. Lehmann, M.; Wallbank, A.M.; Dennis, K.A.; Wufsus, A.R.; Davis, K.M.; Rana, K.; Neeves, K.B. On-chip recalcification of citrated whole blood using a microfluidic herringbone mixer. Biomicrofluidics 2015, 9, 064106. [CrossRef] [PubMed]

42. Plevniak, K.; Campbell, M.; He, M. 3D printed microfluidic mixer for point-of-care diagnosis of anemia. In Proceedings of the 2016 38th Annual International Conference of the IEEE Engineering in Medicine and Biology Society (EMBC), Orlando, FL, USA, 16-20 August 2016; pp. 267-270.

43. Li, Y.; Liu, C.; Feng, X.; Xu, Y.; Liu, B.F. Ultrafast microfluidic mixer for tracking the early folding kinetics of human telomere G-quadruplex. Anal. Chem. 2014, 86, 4333-4339. [CrossRef] [PubMed]

44. Pamme, N. Continuous flow separations in microfluidic devices. Lab Chip 2007, 7, 1644-1659. [CrossRef] [PubMed]

45. Chen, Y.; Li, P.; Huang, P.-H.; Xie, Y.; Mai, J.D.; Wang, L.; Nguyen, N.-T.; Huang, T.J. Rare cell isolation and analysis in microfluidics. Lab Chip 2014, 14, 626-645. [CrossRef] [PubMed]

46. Karle, M.; Vashist, S.K.; Zengerle, R.; Stetten, F.V. Microfluidic solutions enabling continuous processing and monitoring of biological samples: A review. Anal. Chim. Acta 2016, 929, 1-22. [CrossRef] [PubMed]

47. Nguyen, N.T. Micro-magnetofluidics: Interactions between magnetism and fluid flow on the microscale. Microfluid. Nanofluid. 2012, 12,1-16. [CrossRef]

48. Hejazian, M.; Li, W.; Nguyen, N.T. Lab on a chip for continuous-flow magnetic cell separation. Lab Chip 2015, 15, 959-970. [CrossRef] [PubMed]

49. Gijs, M.A.M. Magnetic bead handling on-chip: New opportunities for analytical applications. Microfluid. Nanofluid. 2004, 1, 22-40. [CrossRef]

50. Gijs, M.A.M.; Lacharme, F.; Lehmann, U. Microfluidic Applications of Magnetic Particles for Biological Analysis and Catalysis. Chem. Rev. 2010, 110, 1518-1563. [CrossRef] [PubMed]

51. Pamme, N. Magnetism and microfluidics. Lab Chip 2006, 6, 24-38. [CrossRef] [PubMed]

52. Hejazian, M.; Nguyen, N.-T. Negative magnetophoresis in diluted ferrofluid flow. Lab Chip 2015, 15, 2998-3005. [CrossRef] [PubMed]

53. Hejazian, M.; Nguyen, N.-T. Magnetofluidic concentration and separation of non-magnetic particles using two magnet arrays. Biomicrofluidics 2016, 10, 044103. [CrossRef] [PubMed]

54. Zhou, Y.; Kumar, D.T.; Lu, X.; Kale, A.; DuBose, J.; Song, Y.; Wang, J.; Li, D.; Xuan, X. Simultaneous diamagnetic and magnetic particle trapping in ferrofluid microflows via a single permanent magnet. Biomicrofluidics 2015, 9, 044102. [CrossRef] [PubMed]

55. Afshar, R.; Moser, Y.; Lehnert, T.; Gijs, M.A.M. Three-dimensional magnetic focusing of superparamagnetic beads for on-chip agglutination assays. Anal. Chem. 2011, 83, 1022-1029. [CrossRef] [PubMed]

56. Liang, L.; Xuan, X. Continuous sheath-free magnetic separation of particles in a U-shaped microchannel. Biomicrofluidics 2012, 6, 044106. [CrossRef] [PubMed] 
57. Zhou, R.; Wang, C. Microfluidic separation of magnetic particles with soft magnetic microstructures. Microfluid. Nanofluid. 2016, 20, 48. [CrossRef]

58. Wu, J.; Yan, Q.; Xuan, S.; Gong, X. Size-selective separation of magnetic nanospheres in a microfluidic channel. Microfluid. Nanofluid. 2017, 21, 47. [CrossRef]

59. Zhang, J.; Yan, S.; Yuan, D.; Alici, G.; Nguyen, N.T.; Ebrahimi Warkiani, M.; Li, W. Fundamentals and applications of inertial microfluidics: A review. Lab Chip 2016, 16, 10-34. [CrossRef] [PubMed]

60. Di Carlo, D. Inertial microfluidics. Lab Chip 2009, 9, 3038-3046. [CrossRef] [PubMed]

61. McGrath, J.; Jimenez, M.; Bridle, H. Deterministic lateral displacement for particle separation: A review. Lab Chip 2014, 14, 4139-4158. [CrossRef] [PubMed]

62. Martel, J.M.; Toner, M. Inertial focusing in microfluidics. Annu. Rev. Biomed. Eng. 2014, 16, 371-396. [CrossRef] [PubMed]

63. Nan, X.; Zhu, X.; Ni, Z. Application of inertial effect in microfluidic chips. Prog. Chem. 2011, 23, $1945-1958$.

64. Ahn, S.W.; Lee, S.S.; Lee, S.J.; Kim, J.M. Microfluidic particle separator utilizing sheathless elasto-inertial focusing. Chem. Eng. Sci. 2015, 126, 237-243. [CrossRef]

65. Schaap, A.; Dumon, J.; Toonder, J. Sorting algal cells by morphology in spiral microchannels using inertial microfluidics. Microfluid. Nanofluid. 2016, 20, 125. [CrossRef]

66. Zhou, Y.; Song, L.; Yu, L.; Xuan, X. Inertially focused diamagnetic particle separation in ferrofluids. Microfluid. Nanofluid. 2017, 21, 14. [CrossRef]

67. Clime, L.; Hoa, X.D.; Corneau, N.; Morton, K.J.; Luebbert, C.; Mounier, M.; Brassard, D.; Geissler, M.; Bidawid, S.; Farber, J.; et al. Microfluidic filtration and extraction of pathogens from food samples by hydrodynamic focusing and inertial lateral migration. Biomed. Microdevices 2015, 17, 17. [CrossRef] [PubMed]

68. Barani, A.; Paktinat, H.; Janmaleki, M.; Mohammadi, A.; Mosaddegh, P.; Fadaei-Tehrani, A.; Sanati-Nezhad, A. Microfluidic integrated acoustic waving for manipulation of cells and molecules. Biosens. Bioelectron. 2016, 85, 714-725. [CrossRef] [PubMed]

69. Sadhal, S.S. Acoustofluidics 15: Streaming with sound waves interacting with solid particles. Lab Chip 2012, 12, 2600-2611. [CrossRef] [PubMed]

70. Wiklund, M.; Green, R.; Ohlin, M. Acoustofluidics 14: Applications of acoustic streaming in microfluidic devices. Lab Chip 2012, 12, 2438-2451. [CrossRef] [PubMed]

71. Voiculescu, I.; Nordin, A.N. Acoustic wave based MEMS devices for biosensing applications. Biosens. Bioelectron. 2012, 33, 1-9. [CrossRef] [PubMed]

72. Nam, J.; Lim, H.; Shin, S. Manipulation of microparticles using surface acoustic wave in microfluidic systems: A brief review. Korea Aust. Rheol. J. 2011, 23, 255-267. [CrossRef]

73. Länge, K.; Rapp, B.E.; Rapp, M. Surface acoustic wave biosensors: A review. Anal. Bioanal. Chem. 2008, 391, 1509-1519. [CrossRef] [PubMed]

74. Mathew, B.; Alazzam, A.; El-Khasawneh, B.; Maalouf, M.; Destgeer, G.; Sung, H.J. Model for tracing the path of microparticles in continuous flow microfluidic devices for 2D focusing via standing acoustic waves. Sep. Purif. Technol. 2015, 153, 99-107. [CrossRef]

75. Shields, C.W.I.; Wang, J.L.; Ohiri, K.A.; Essoyan, E.D.; Yellen, B.B.; Armstrong, A.J.; López, G.P. Magnetic separation of acoustically focused cancer cells from blood for magnetographic templating and analysis. Lab Chip 2016, 16, 3833-3844. [CrossRef] [PubMed]

76. Ng, J.W.; Collins, D.J.; Devendran, C.; Ai, Y.; Neild, A. Flow-rate-insensitive deterministic particle sorting using a combination of travelling and standing surface acoustic waves. Microfluid. Nanofluid. 2016, 20. [CrossRef]

77. Devi, U.V.; Puri, P.; Sharma, N.N.; Ananthasubramanian, M. Electrokinetics of Cells in Dielectrophoretic Separation: A Biological Perspective. BioNanoScience 2014, 4, 276-287. [CrossRef]

78. Jubery, T.Z.; Srivastava, S.K.; Dutta, P. Dielectrophoretic separation of bioparticles in microdevices: A review. Electrophoresis 2014, 35, 691-713. [CrossRef] [PubMed]

79. Dash, S.; Mohanty, S. Dielectrophoretic separation of micron and submicron particles: A review. Electrophoresis 2014, 35, 2656-2672. [CrossRef] [PubMed]

80. Khoshmanesh, K.; Nahavandi, S.; Baratchi, S.; Mitchell, A.; Kalantar-zadeh, K. Dielectrophoretic platforms for bio-microfluidic systems. Biosens. Bioelectron. 2011, 26, 1800-1814. [CrossRef] [PubMed]

81. Zhang, C.; Khoshmanesh, K.; Mitchell, A.; Kalantar-Zadeh, K. Dielectrophoresis for manipulation of micro/nano particles in microfluidic systems. Anal. Bioanal. Chem. 2010, 396, 401-420. [CrossRef] [PubMed] 
82. Cui, H.H.; Voldman, J.; He, X.F.; Lim, K.M. Separation of particles by pulsed dielectrophoresis. Lab Chip 2009, 9, 2306-2312. [CrossRef] [PubMed]

83. Kim, U.; Soh, H.T. Simultaneous sorting of multiple bacterial targets using integrated Dielectrophoretic-Magnetic Activated Cell Sorter. Lab Chip 2009, 9, 2313-2318. [CrossRef] [PubMed]

84. Yan, S.; Zhang, J.; Yuan, Y.; Lovrecz, G.; Alici, G.; Du, H.; Zhu, Y.; Li, W. A hybrid dielectrophoretic and hydrophoretic microchip for particle sorting using integrated prefocusing and sorting steps. Electrophoresis 2015, 36, 284-291. [CrossRef] [PubMed]

85. Kotari, H.; Motosuke, M. Simple applications of microparticle transportation by tender optical scattering force. Microfluid. Nanofluid. 2015, 18, 549-558. [CrossRef]

86. Kuo, J.-N.; Li, B.-S. Lab-on-CD microfluidic platform for rapid separation and mixing of plasma from whole blood. Biomed. Microdevices 2014, 16, 549-558. [CrossRef] [PubMed]

87. Tallapragada, P.; Hasabnis, N.; Katuri, K.; Sudarsanam, S.; Joshi, K.; Ramasubramanian, M. Scale invariant hydrodynamic focusing and sorting of inertial particles by size in spiral micro channels. J. Micromech. Microeng. 2015, 25, 084013. [CrossRef]

88. Millet, L.J.; Lucheon, J.D.; Standaert, R.F.; Retterer, S.T.; Doktycz, M.J. Modular microfluidics for point-of-care protein purifications. Lab Chip 2015, 15, 1799-1811. [CrossRef] [PubMed]

89. Freire, S.L.S. Perspectives on digital microfluidics. Sens. Actuators A Phys. 2016, 250, 15-28. [CrossRef]

90. Mashaghi, S.; Abbaspourrad, A.; Weitz, D.A.; van Oijen, A.M. Droplet microfluidics: A tool for biology, chemistry and nanotechnology. TrAC Trends Anal. Chem. 2016, 82, 118-125. [CrossRef]

91. Shembekar, N.; Chaipan, C.; Utharala, R.; Merten, C.A. Droplet-based microfluidics in drug discovery, transcriptomics and high-throughput molecular genetics. Lab Chip 2016, 16, 1314-1331. [CrossRef] [PubMed]

92. Pollack, M.G.; Shenderov, A.D.; Fair, R.B. Electrowetting-based actuation of droplets for integrated microfluidics. Lab Chip 2002, 2, 96-101. [CrossRef] [PubMed]

93. Geng, H.; Feng, J.; Stabryla, L.M.; Cho, S.K. Dielectrowetting manipulation for digital microfluidics: Creating, transporting, splitting, and merging of droplets. Lab Chip 2017, 17, 1060-1068. [CrossRef] [PubMed]

94. Aijian, A.P.; Garrell, R.L. Digital Microfluidics for Automated Hanging Drop Cell Spheroid Culture. J. Lab. Autom. 2015, 20, 283-295. [CrossRef] [PubMed]

95. Pei, S.N.; Valley, J.K.; Neale, S.L.; Jamshidi, A.; Hsu, H.Y.; Wu, M.C. Light-actuated digital microfluidics for large-scale, parallel manipulation of arbitrarily sized droplets. In Proceedings of the 2010 IEEE 23rd International Conference on Micro Electro Mechanical Systems (MEMS), Hong Kong, China, 24-28 January 2010; pp. 252-255.

96. Chiou, P.Y.; Moon, H.; Toshiyoshi, H.; Kim, C.-J.; Wu, M.C. Light actuation of liquid by optoelectrowetting. Sens. Actuators A Phys. 2003, 104, 222-228. [CrossRef]

97. McHale, G.; Brown, C.V.; Newton, M.I.; Wells, G.G.; Sampara, N. Dielectrowetting Driven Spreading of Droplets. Phys. Rev. Lett. 2011, 107, 186101. [CrossRef] [PubMed]

98. Peng, C.; Wang, Y.; Sungtaek Ju, Y. Finger-powered electrophoretic transport of discrete droplets for portable digital microfluidics. Lab Chip 2016, 16, 2521-2531. [CrossRef] [PubMed]

99. Hunt, T.P.; Issadore, D.; Westervelt, R.M. Integrated circuit/microfluidic chip to programmably trap and move cells and droplets with dielectrophoresis. Lab Chip 2008, 8, 81-87. [CrossRef] [PubMed]

100. Iwai, K.; Shih, K.C.; Lin, X.; Brubaker, T.A.; Sochol, R.D.; Lin, L. Finger-powered microfluidic systems using multilayer soft lithography and injection molding processes. Lab Chip 2014, 14, 3790-3799. [CrossRef] [PubMed]

101. Nguyen, N.T.; Zhu, G.P.; Chua, Y.C.; Phan, V.N.; Tan, S.H. Magnetowetting and Sliding Motion of a Sessile Ferrofluid Droplet in the Presence of a Permanent Magnet. Langmuir 2010, 26, 12553-12559. [CrossRef] [PubMed]

102. Monkkonen, L.; Edgar, J.S.; Winters, D.; Heron, S.R.; Mackay, C.L.; Masselon, C.D.; Stokes, A.A.; Langridge-Smith, P.R.R.; Goodlett, D.R. Screen-printed digital microfluidics combined with surface acoustic wave nebulization for hydrogen-deuterium exchange measurements. J. Chromatogr. A 2016, 1439, 161-166. [CrossRef] [PubMed]

103. Renaudin, A.; Tabourier, P.; Camart, J.-C.; Druon, C. Surface acoustic wave two-dimensional transport and location of microdroplets using echo signal. J. Appl. Phys. 2006, 100, 116101. [CrossRef]

104. Guttenberg, Z.; Muller, H.; Habermuller, H.; Geisbauer, A.; Pipper, J.; Felbel, J.; Kielpinski, M.; Scriba, J.; Wixforth, A. Planar chip device for PCR and hybridization with surface acoustic wave pump. Lab Chip 2005, 5, 308-317. [CrossRef] [PubMed] 
105. Chen, J.Z.; Troian, S.M.; Darhuber, A.A.; Wagner, S. Effect of contact angle hysteresis on thermocapillary droplet actuation. J. Appl. Phys. 2005, 97, 014906. [CrossRef]

106. Darhuber, A.A.; Valentino, J.P.; Troian, S.M.; Wagner, S. Thermocapillary actuation of droplets on chemically patterned surfaces by programmable microheater arrays. J. Microelectromech. Syst. 2003, 12, 873-879. [CrossRef]

107. Nguyen, N.-T.; Huang, X. Thermocapillary effect of a liquid plug in transient temperature fields. Jpn. J. Appl. Phys. 2005, 44, 1139-1142. [CrossRef]

108. Aussillous, P.; Quere, D. Properties of liquid marbles. Proc. R. Soc. A Math. Phys. Eng. Sci. 2006, 462, 973-999. [CrossRef]

109. McHale, G.; Newton, M.I. Liquid marbles: Principles and applications. Soft Matter 2011, 7, 5473-5481. [CrossRef]

110. McHale, G.; Newton, M.I. Liquid marbles: Topical context within soft matter and recent progress. Soft Matter 2015, 11, 2530-2546. [CrossRef] [PubMed]

111. Bormashenko, E. New insights into liquid marbles. Soft Matter 2012, 8, 11018-11021. [CrossRef]

112. Cengiz, U.; Erbil, H.Y. The lifetime of floating liquid marbles: The influence of particle size and effective surface tension. Soft Matter 2013, 9, 8980-8991. [CrossRef]

113. Bormashenko, E.; Pogreb, R.; Musin, A. Stable water and glycerol marbles immersed in organic liquids: From liquid marbles to Pickering-like emulsions. J. Colloid Interface Sci. 2012, 366, 196-199. [CrossRef] [PubMed]

114. Ooi, C.H.; Nguyen, A.V.; Evans, G.M.; Dao, D.V.; Nguyen, N.T. Measuring the Coefficient of Friction of a Small Floating Liquid Marble. Sci. Rep. 2016, 6, 38346. [CrossRef] [PubMed]

115. Ooi, C.H.; Plackowski, C.; Nguyen, A.V.; Vadivelu, R.K.; John, J.A.S.; Dao, D.V.; Nguyen, N.-T. Floating mechanism of a small liquid marble. Sci. Rep. 2016, 6, 21777. [CrossRef] [PubMed]

116. Ooi, C.H.; Nguyen, N.-T. Manipulation of liquid marbles. Microfluid. Nanofluid. 2015, 19, 483-495. [CrossRef]

117. Khaw, M.K.; Ooi, C.H.; Mohd-Yasin, F.; Vadivelu, R.; John, J.S.; Nguyen, N.-T. Digital microfluidics with a magnetically actuated floating liquid marble. Lab Chip 2016, 16, 2211-2218. [CrossRef] [PubMed]

118. Xue, Y.; Wang, H.; Zhao, Y.; Dai, L.; Feng, L.; Wang, X.; Lin, T. Magnetic Liquid Marbles: A "Precise" Miniature Reactor. Adv. Mater. 2010, 22, 4814-4818. [CrossRef] [PubMed]

119. Zhao, Y.; Fang, J.; Wang, H.; Wang, X.; Lin, T. Magnetic Liquid Marbles: Manipulation of Liquid Droplets Using Highly Hydrophobic $\mathrm{Fe}_{3} \mathrm{O}_{4}$ Nanoparticles. Adv. Mater. 2010, 22, 707-710. [CrossRef] [PubMed]

120. Zhao, Y.; Xu, Z.G.; Parhizkar, M.; Fang, J.; Wang, X.G.; Lin, T. Magnetic liquid marbles, their manipulation and application in optical probing. Microfluid. Nanofluid. 2012, 13, 555-564. [CrossRef]

121. Zhang, L.; Cha, D.; Wang, P. Remotely Controllable Liquid Marbles. Adv. Mater. 2012, 24, 4756-4760. [CrossRef] [PubMed]

122. Paven, M.; Mayama, H.; Sekido, T.; Butt, H.-J.; Nakamura, Y.; Fujii, S. Liquid Marbles: Light-Driven Delivery and Release of Materials Using Liquid Marbles (Adv Funct. Mater. 19/2016). Adv. Funct. Mater. 2016, 26, 3372. [CrossRef]

123. Kavokine, N.; Anyfantakis, M.; Morel, M.; Rudiuk, S.; Bickel, T.; Baigl, D. Light-Driven Transport of a Liquid Marble with and against Surface Flows. Angew. Chem. Int. Ed. 2016, 55, 11183-11187. [CrossRef] [PubMed]

124. Bormashenko, E.; Bormashenko, Y.; Grynyov, R.; Aharoni, H.; Whyman, G.; Binks, B.P. Self-Propulsion of Liquid Marbles: Leidenfrost-like Levitation Driven by Marangoni Flow. J. Phys. Chem. C 2015, 119, 9910-9915. [CrossRef]

125. Ooi, C.H.; Nguyen, A.V.; Evans, G.M.; Gendelman, O.; Bormashenko, E.; Nguyen, N.-T. A floating self-propelling liquid marble containing aqueous ethanol solutions. RSC Adv. 2015, 5, 101006-101012. [CrossRef]

126. Bormashenko, E. Liquid Marbles, Elastic Nonstick Droplets: From Minireactors to Self-Propulsion. Langmuir 2017, 33, 663-669. [CrossRef] [PubMed]

127. Seale, B.; Lam, C.; Rackus, D.G.; Chamberlain, M.D.; Liu, C.; Wheeler, A.R. Digital Microfluidics for Immunoprecipitation. Anal. Chem. 2016, 88, 10223-10230. [CrossRef] [PubMed]

128. Mei, N.; Seale, B.; Ng, A.H.C.; Wheeler, A.R.; Oleschuk, R. Digital microfluidic platform for human plasma protein depletion. Anal. Chem. 2014, 86, 8466-8472. [CrossRef] [PubMed]

129. Ng, A.H.C.; Choi, K.; Luoma, R.P.; Robinson, J.M.; Wheeler, A.R. Digital microfluidic magnetic separation for particle-based immunoassays. Anal. Chem. 2012, 84, 8805-8812. [CrossRef] [PubMed] 
130. Choi, K.; Boyac1, E.; Kim, J.; Seale, B.; Barrera-Arbelaez, L.; Pawliszyn, J.; Wheeler, A.R. A digital microfluidic interface between solid-phase microextraction and liquid chromatography-mass spectrometry. J. Chromatogr. A 2016, 1444, 1-7. [CrossRef] [PubMed]

131. Swyer, I.; Soong, R.; Dryden, M.D.M.; Fey, M.; Maas, W.E.; Simpson, A.; Wheeler, A.R. Interfacing digital microfluidics with high-field nuclear magnetic resonance spectroscopy. Lab Chip 2016, 16, 4424-4435. [CrossRef] [PubMed]

132. Heinemann, J.; Deng, K.; Shih, S.C.C.; Gao, J.; Adams, P.D.; Singh, A.K.; Northen, T.R. On-chip integration of droplet microfluidics and nanostructure-initiator mass spectrometry for enzyme screening. Lab Chip 2017, 17, 323-331. [CrossRef] [PubMed]

133. Zeng, Z.; Zhang, K.; Wang, W.; Xu, W.; Zhou, J. Portable electrowetting digital microfluidics analysis platform for chemiluminescence sensing. IEEE Sens. J. 2016, 16, 4531-4536. [CrossRef]

134. Arbatan, T.; Al-Abboodi, A.; Sarvi, F.; Chan, P.P.; Shen, W. Tumor inside a pearl drop. Adv. Healthc. Mater. 2012, 1, 467-469. [CrossRef] [PubMed]

135. Sarvi, F.; Jain, K.; Arbatan, T.; Verma, P.J.; Hourigan, K.; Thompson, M.C.; Shen, W.; Chan, P.P. Cardiogenesis of embryonic stem cells with liquid marble micro-bioreactor. Adv. Healthc. Mater. 2015, 4, 77-86. [CrossRef] [PubMed]

136. Vadivelu, R.K.; Ooi, C.H.; Yao, R.-Q.; Tello Velasquez, J.; Pastrana, E.; Diaz-Nido, J.; Lim, F.; Ekberg, J.A.K.; Nguyen, N.-T.; St John, J.A. Generation of three-dimensional multiple spheroid model of olfactory ensheathing cells using floating liquid marbles. Sci. Rep. 2015, 5, 15083. [CrossRef] [PubMed]

137. Tian, J.; Fu, N.; Chen, X.D.; Shen, W. Respirable liquid marble for the cultivation of microorganisms. Colloids Surf. B 2013, 106, 187-190. [CrossRef] [PubMed]

138. Eshtiaghi, N.; Hapgood, K.P. A quantitative framework for the formation of liquid marbles and hollow granules from hydrophobic powders. Powder Technol. 2012, 223, 65-76. [CrossRef]

139. Zhang, G.; Wang, C. Pickering emulsion-based marbles for cellular capsules. Materials 2016, 9, 572. [CrossRef]

140. Arbatan, T.; Li, L.; Tian, J.; Shen, W. Liquid marbles as micro-bioreactors for rapid blood typing. Adv. Healthc. Mater. 2012, 1, 80-83. [CrossRef] [PubMed]

141. Han, X.; Lee, H.K.; Lim, W.C.; Lee, Y.H.; Phan-Quang, G.C.; Phang, I.Y.; Ling, X.Y. Spinning Liquid Marble and Its Dual Applications as Microcentrifuge and Miniature Localized Viscometer. ACS Appl. Mater. Interfaces 2016, 8, 23941-23946. [CrossRef] [PubMed] 